\title{
Anti-type II collagen antibodies, anti-CCP, IgA RF and IgM RF are associated with joint damage, assessed eight years after onset of juvenile idiopathic arthritis (JIA)
}

Lillemor Berntson ${ }^{1 *}$, Ellen Nordal ${ }^{2,3}$, Anders Fasth $^{4}$, Kristiina Aalto ${ }^{5}$, Troels Herlin ${ }^{6}$, Susan Nielsen ${ }^{7}$, Marite Rygg ${ }^{8,9}$, Marek Zak ${ }^{7}$, Johan Rönnelid ${ }^{10}$ for the Nordic Study Group of Pediatric Rheumatology (NoSPeR)

\begin{abstract}
Background: Early appearance of antibodies specific for native human type II collagen (anti-CII) characterizes an early inflammatory and destructive phenotype in adults with rheumatoid arthritis (RA). The objective of this study was to investigate the occurrence of anti-Cll, IgM RF, IgA RF and anti-CCP in serum samples obtained early after diagnosis, and to relate the occurrence of autoantibodies to outcome after eight years of disease in children with juvenile idiopathic arthritis (JIA).
\end{abstract}

Methods: The Nordic JIA database prospectively included JIA patients followed for eight years with data on remission and joint damage. From this database, serum samples collected from 192 patients, at a median of four months after disease onset, were analysed for IgG anti-Cll, IgM RF, IgA RF and IgG anti-CCP. Joint damage was assessed based on Juvenile Arthritis Damage Index for Articular damage (JADI-A), a validated clinical instrument for joint damage.

Results: Elevated serum levels of anti-Cll occurred in 3.1\%, IgM RF in 3.6\%, IgA RF in 3.1\% and anti-CCP in 2.6\% of the patients. Occurrence of RF and anti-CCP did to some extent overlap, but rarely with anti-Cll. The polyarticular and oligoarticular extended categories were overrepresented in patients with two or more autoantibodies. Anti-Cll occurred in younger children, usually without overlap with the other autoantibodies and was associated with high levels of C-reactive protein (CRP) early in the disease course. All four autoantibodies were significantly associated with joint damage, but not with active disease at the eight-year follow up.

Conclusions: Anti-Cll, anti-CCP, IgA RF and IgM RF detected early in the disease course predicted joint damage when assessed after eight years of disease. The role of anti-CII in JIA should be further studied.

Keywords: Arthritis, Juvenile Idiopathic Arthritis, Anti-CCP, Rheumatoid factor, Anti-collagen type II antibodies, Child, Joints

\section{Background}

Juvenile idiopathic arthritis (JIA) is a heterogeneous condition with time of onset before the age of 16 . The diversity in clinical manifestations differs from that in adult arthritis, but some findings point to similarities among children and adults. Reliable biomarkers for prediction of outcome and choice of treatment in JIA are scarce [1].

\footnotetext{
* Correspondence: lillemor.berntson@telia.com

'Department of Women's and Children's Health, Uppsala University, Uppsala, Sweden

Full list of author information is available at the end of the article
}

JIA is currently described by the International League of Associations for Rheumatism (ILAR) classification system as a disease comprising seven categories, based on clinical characteristics, heredity and laboratory results [2]. While IgM rheumatoid factor (RF) is a determinant of the polyarticular categories, occurrence of IgA RF and anticitrullinated peptide antibodies (ACPA), for which the most common clinical test is anti-cyclic citrullinated peptide (anti-CCP), are not included in the ILAR classification.

In population-based studies on JIA, IgM RF has an occurrence rate of $2-3 \%[3,4]$ and defines a subset of JIA 
resembling that of rheumatoid arthritis (RA) with a polyarticular disease, higher age at onset and a higher risk of joint damage. IgA RF has been studied far less, but is also discussed as a risk factor for joint space narrowing or joint erosions [5].

In RA, anti-CCP can be detected several years before disease onset [6], has a high disease specificity, and is now included in the 2010 classification criteria for RA [7]. The prognostic role of anti-CCP in JIA resembles that of IgM RF. Anti-CCP has low prevalence (2-15\%) and is present in particular in the RF-positive, polyarticular JIA category [8-10]. The majority of JIA study cohorts on ACPA are small. Results depend on the methods used for analysis, cut-off values for autoantibody analyses and patient selection.

Autoantibodies against collagen type II (anti-CII) have been studied in adult RA $(11-14)$. CII is the predominant hyaline cartilage collagen. Patients with anti-CII make up a distinct RA phenotype, found in a minority of adult RA patients, associated with acute inflammation at disease onset [11] and early radiographic destruction [12]. Anti-CII has been shown to induce the proinflammatory cytokines TNF $\alpha$, IL- $1 \beta$ and IL-8, when incorporated in immune complexes in vitro [13]. These findings are in concordance with earlier reports showing that high anti-CII levels are associated with higher levels of ESR, CRP, TNF $\alpha$ and IL- 6 compared with what is found in anti-CII negative RA patients [14]. Anti-CII positive RA patients also experience less diagnostic delay [11], probably because of the high inflammatory activity. In contrast to ACPA and RF, anti-CII does not precede the development of RA by a long time period $[6,15]$. Earlier studies have shown that levels of anti-CII decrease shortly after RA diagnosis $[11,16]$, and therefore studies of antiCII should preferably be performed on sera obtained early at or soon after disease onset. The anti-CII phenotype in adult RA thus seems to be a temporary finding around the time of symptom onset and diagnosis [12]. Data regarding anti-CII in JIA are scarce [17].

Our aim was to study whether early occurrence of antiCII, IgM RF, IgA RF and/or anti-CCP, in a well-defined cohort of children with JIA, could be related to outcome data and joint damage after eight years of disease.

\section{Methods}

\section{Patients}

The Nordic JIA database consists of 440 patients followed prospectively for a median of 97 months (IQR 95-105) in a population-based approach and classified according to the ILAR criteria after eight years of disease [2]. From this database, 192 patients with (available) sera taken within 12 months after disease onset were included. Due to these inclusion criteria, this sub-study cannot be considered population-based. Data of CRP results $\leq 10$ months after disease onset were included if available. At the eight-year follow-up visit, remission according to the preliminary criteria of Wallace et al. [18], and joint damage according to Juvenile Arthritis Damage Index for Articular damage (JADI-A) (scale 0-72 where 0 means no damage) [19], were assessed by a paediatric rheumatologist in 147 of the patients. We found no statistical difference between the original 440 patients and the 147 patients studied as regards gender, age of onset or proportion of oligoarticular persistent patients.

\section{Analyses of autoantibodies}

For autoantibody analyses we used sera stored at $-70^{\circ} \mathrm{C}$, collected within a median of four months (IQR 2-7) after disease onset. IgM RF, IgA RF and anti-CCP were analysed using the Phadia ImmunoCAP enzyme immunoassay, allowing isotype-specific analysis of IgM and IgA RF. For anti-CCP, the cut-off value at Uppsala University Hospital of $>7 \mathrm{U} / \mathrm{ml}$ was used, which is a commonly used cut-off value in many laboratories. The reference ranges for $\operatorname{IgM}(>5 \mathrm{U} / \mathrm{ml})$ and IgA RF $(>9 \mathrm{U} / \mathrm{ml})$ were established with 100 healthy adult donors, using the reference range criteria ( $>95 \%$ diagnostic specificity) determined based on the 1987 ACR RA classification criteria [20]. Analysis of anti-CII IgG was performed with an in-house enzymelinked immunosorbent assay (ELISA), using the cut-off $(>29 \mathrm{U} / \mathrm{ml})$ set at $95 \%$ specificity among 100 healthy adult blood donors as described earlier [11,12].

\section{Statistical methods}

Conventional descriptive statistics were used; median and interquartile ranges (IQR) were given. For independent samples the Mann-Whitney $U$ test was used and for analysis of proportions Fisher's exact test was employed, due to the low number of antibody-positive patients. Correlations were assessed using Spearman's rank correlation coefficients $(\rho)$. P-values of less than 0.05 were considered statistically significant for two-tailed tests. Analyses were carried out using the Statistical Package for Social Sciences (SPSS), version 20 (IBM SPSS Statistics) and JMP (SAS Institute).

\section{Ethical issues}

The Research Ethical Committees in each country gave their approval in accordance with national practice and legislation. In Sweden the study was approved by the Regional Ethical Review Board at Uppsala. Written informed consent was obtained from patients $>16$ years and from parents for children aged $<16$ years.

\section{Results}

All ILAR categories were represented in the patient cohort, of which $69.3 \%$ were female (Table 1). The oligoarticular persistent group was the largest (46.9\% of the total cohort). 
Elevated levels of anti-CII were found in $3.1 \%$ of the serum samples, IgM RF in $3.6 \%$, IgA RF in $3.1 \%$, anti-CCP in $2.6 \%$.

Occurrence of RF and anti-CCP did overlap to some extent, but rarely with anti-CII (Table 2 ). The polyarticular and oligoarticular extended categories were overrepresented in patients with two or more of the four autoantibodies present. In two patients (patients 8 and 9 in Table 2), the anti-CCP value was more than ten times higher than in other anti-CCP positive patients.

The median age of onset was significantly higher in patients with IgM as compared with patients without these antibodies, while patients with anti-CII had onset ages comparable to those of the total JIA cohort (Table 3). JADIA for joint damage was assessed in 147 patients and found to be $>0$ in 18 patients. All four autoantibodies were significantly associated with joint damage according to JADI-A after eight years, with the strongest associations found for IgA RF and anti-CCP (Table 3). The occurrence of any of the investigated autoantibodies was also strongly associated with elevated JADI-A $(p=0.0004$, Table 3$)$. There was, however, no significant association between the presence of these autoantibodies and cumulative number of joints affected, ongoing disease activity, or remission at eight years.

When patient antibodies were correlated to the JADIA scores, we found a highly significant association to the number of antibodies detected $(\mathrm{p}=0.0001)$. The correlation coefficients were, however, low for the commonly tested antibodies (anti-CCP, IgM RF and IgA RF) (Spearman's $\rho=0.30)$ and did not increase when anti-CII were included (Spearman's $\rho=0.31$ ).

Information on CRP levels taken $\leq 10$ months after disease onset were available for $134 / 192$ patients. CRP taken early in the disease course were significantly higher (more than four times higher) in anti-CII positive patients than in anti-CII negative patients (median 30.0 vs. $8.7 \mathrm{mg} / \mathrm{l} ; \mathrm{p}=0.0001)$. No such association was found for any of the other antibodies studied (Figure 1).

\section{Discussion}

As far as we know, this is the first study investigating the long-term prognostic impact of antibodies against native CII in JIA. Occurrence of anti-CII rarely overlapped with anti-CCP, IgA RF and IgM RF, and was seen in a younger age group at disease onset than the other three conventional autoantibodies. All four autoantibodies were associated with clinical assessment of joint damage according to JADI-A after a median of eight years of disease.

A strength of this study is that it includes all JIA categories, and that analysed serum samples were collected early in the disease course. This is in contrast to other studies on autoantibodies in JIA, where samples have been collected at different times after disease onset. This early sampling was also a prerequisite for the analysis of anti-CII, as previous studies have shown that anti-CII levels peak around the time of RA diagnosis [11].

Limitations of our study were the small number of autoantibody-positive patients, and that no data on radiological damage was available for assessment of joint damage. The JADI-A index used in this study is validated and considered useful as an instrument for the clinical assessment of long-term articular damage in patients with JIA, but the index mainly collects severe articular changes [19]. Radiographical methods do not fully reflect the spectrum of articular damage in children since contractures and restricted range of movement can also depend on extraarticular damage. An advantage of using the JADI-A is that it includes restricted range of movement and joint damage not necessarily detected by radiography. A limitation is that autoantibodies were analysed at only one time point, which might include false positive serum samples. In order to be classified as RF-positive JIA, two positive tests at least three months apart are required (2). Adult and not age-matched cut-off values were used for the conventionally used autoantibodies (IgM RF, IgA RF and anti-CCP) [17]. We therefore

Table 1 Prevalence of autoantibodies during the first year of disease in 192 patients from the Nordic juvenile idiopathic arthritis database classified after a median of eight years of disease according to the ILAR* criteria

\begin{tabular}{|c|c|c|c|c|c|c|}
\hline ILAR* category & $\begin{array}{l}\text { Total cohort } \\
\text { n (\%) }\end{array}$ & $\begin{array}{l}\text { Girls/boys } \\
\text { n (\% girls) }\end{array}$ & $\begin{array}{l}\text { IgM RF- positive } \\
\text { n (\%) }\end{array}$ & $\begin{array}{l}\text { IgA RF-positive } \\
\text { n (\%) }\end{array}$ & $\begin{array}{l}\text { IgG anti-CCP } \\
\text { positive } \mathrm{n}(\%)\end{array}$ & $\begin{array}{l}\text { IgG anti-collagen } \\
\text { II positive } \mathrm{n}(\%)\end{array}$ \\
\hline Systemic & $9(4.7 \%)$ & $5 / 4(55 \%)$ & 1 & 0 & 1 & 0 \\
\hline Oligoarticular persistent & $90(46.9 \%)$ & $60 / 30(66.6 \%)$ & 2 & - & - & 2 \\
\hline Oligoarticular extended & $8(4.2 \%)$ & $8 / 0(100 \%)$ & 1 & 1 & 1 & - \\
\hline Polyarticular RF-negative & $40(20.8 \%)$ & $30 / 10(75.0 \%)$ & - & 1 & 1 & 2 \\
\hline Polyarticular RF-positive & 1 & $1 / 0$ & 1 & 1 & - & - \\
\hline Juvenile psoriatic arthritis & 1 & $0 / 1$ & - & - & - & - \\
\hline Enthesitis-related arthritis & $15(7.8 \%)$ & 5/10 (33.3\%) & - & 2 & 1 & 1 \\
\hline Undifferentiated arthritis & $28(14.6 \%)$ & $24 / 4(85.7 \%)$ & 2 & 1 & 1 & 1 \\
\hline Total & 192 & 133/59 (69.3\%) & $7(3.6 \%)$ & $6(3.1 \%)$ & $5(2.6 \%)$ & $6(3.1 \%)$ \\
\hline
\end{tabular}

*International League of Associations for Rheumatology classification criteria [2]. 
Table 2 Patterns of autoantibodies collected in 17 of 192 patients from the Nordic juvenile idiopathic arthritis database

\begin{tabular}{|c|c|c|c|c|c|c|c|c|}
\hline $\begin{array}{l}\text { Patient } \\
\text { No }\end{array}$ & $\begin{array}{l}\text { Age at time } \\
\text { of onset } \\
\text { Years }\end{array}$ & $\begin{array}{l}\text { IgM RF } \\
\text { Cut-off } \\
>5 \mathrm{U} / \mathrm{ml}\end{array}$ & $\begin{array}{l}\text { IgA RF } \\
\text { Cut-off } \\
>9 \mathrm{U} / \mathrm{ml}\end{array}$ & $\begin{array}{l}\text { IgG Anti-CCP } \\
\text { Cut-off } \\
>7 \mathrm{U} / \mathrm{ml}\end{array}$ & $\begin{array}{l}\text { IgG Anti-Collagen II } \\
\text { Cut-off } \\
>29 \mathrm{U} / \mathrm{ml}\end{array}$ & $\begin{array}{l}\text { Articular } \\
\text { damage }^{\alpha}\end{array}$ & JIA category ${ }^{\#}$ & $\begin{array}{l}\text { Cumulative number } \\
\text { of joints affected } \\
\text { during the first eight } \\
\text { years of disease }\end{array}$ \\
\hline 1 & 4.4 & 5.7 & - & - & - & Missing & Systemic & 4 \\
\hline 2 & 12.8 & 6.0 & - & - & - & - & Oligoarticular persistent & 2 \\
\hline 3 & 13.5 & 23.0 & - & - & - & - & Undifferentiated $^{*}$ & 1 \\
\hline 4 & 9.4 & 5.5 & - & - & - & - & Oligoarticular persistent & 2 \\
\hline 5 & 9.3 & - & 13.0 & - & - & - & Enthesitis-related arthritis & 4 \\
\hline 6 & 1.5 & - & 14.0 & - & - & 1 & Oligoarticular extended & 18 \\
\hline 7 & 13.2 & 64.0 & 17.0 & - & - & 1 & Polyarticular RF-positive & 13 \\
\hline 8 & 13.3 & 132.0 & 67.0 & $\geq 340$ & - & 1 & Undifferentiated $^{* *}$ & 18 \\
\hline 9 & 10.9 & 17.0 & - & $\geq 340$ & - & 1 & Oligoarticular extended & 24 \\
\hline 10 & 1.1 & - & - & 9.8 & - & - & Systemic & 6 \\
\hline 11 & 11.8 & - & 23.0 & 15.0 & - & - & Enthesitis-related arthritis & 2 \\
\hline 12 & 11.0 & - & 11.0 & 12.0 & 94.3 & 1 & Polyarticular RF-negative & 19 \\
\hline 13 & 11.7 & - & - & - & 35.9 & 1 & Polyarticular RF-negative & 34 \\
\hline 14 & 4.0 & - & - & - & 46.6 & - & Enthesitis-related arthritis & 13 \\
\hline 15 & 4.8 & - & - & - & 30.4 & - & Oligoarticular extended & 9 \\
\hline 16 & 4.3 & - & - & - & 72.9 & - & Undifferentiated $^{* * *}$ & 2 \\
\hline 17 & 8.1 & - & - & - & 230.8 & Missing & Oligoarticular persistent & 1 \\
\hline
\end{tabular}

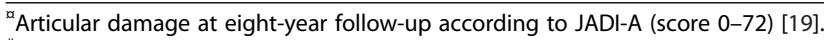

\#ILAR Edmonton criteria after eight years of disease [2].

* Oligoarticular persistent joint pattern and presence of IgM rheumatoid factor on two occasions more than three months apart.

${ }^{* *}$ Polyarticular pattern from onset and psoriasis in first degree relative.

*** Oligoarticular persistent joint pattern and psoriasis in first degree relative.

decided to use adult cut-off levels also for anti-CII. All cut-off values were locally validated using 100 healthy individuals, and specificities adjusted to 95-97\% according to the currently used definition of RF specificity as defined in the previous ACR classification criteria for RA [20], not changed in the more recent EULAR/ACR criteria [7].

Occurrence of autoantibodies was rare in our study, much like in the majority of previous studies on JIA [9,21-23]. As in adult RA, occurrence of IgM RF in JIA has been shown to correlate with joint damage or joint space narrowing [5,17,22,24-26]. Our results were in line with these studies, as we found a significant association with joint damage in the IgM RF-positive patients.

Children with oligoarticular JIA have occasionally been found to be IgM RF-positive. Our results gave no indications of a more severe disease in these children. The three IgM RF-positive patients in our study with high age at onset and oligoarticular joint pattern throughout the disease course did not have any joint damage after eight years of disease. These patients also lacked any of the other autoantibodies investigated in the study. This might indicate that positive IgM RF in an oligoarticular disease is of little significance if the patient lacks antiCCP or IgA RF.
Several studies on JIA point to a high co-occurrence of IgM RF and anti-CCP $[8,26,27]$, but they may also occur independently [28]. JIA patients with IgM RF and/or antiCCP generally present at a higher age than patients without these antibodies [29]. In line with these results, the IgM RF-positive children with articular damage in our study had a high age at onset, a polyarticular or oligoarticular extended disease pattern, and were IgA RF or anti-CCP positive as well. The anti-CCP levels in these children were also very high. It has been suggested that JIA patients positive for both IgM RF and anti-CCP present a more severe disease phenotype than those with only one autoantibody [30]. In line with this, we can report that co-occurrence of IgA $\mathrm{RF}$ and possibly of anti-CII is associated with severe joint damage after eight years of disease in JIA.

We found an association between anti-CCP and joint damage. This is supported by several earlier studies showing an increased risk for radiological bone damage in patients with anti-CCP in JIA $[17,22,26,28]$. Four of five antiCCP positive patients in our study were more than 10 years old at onset; the fifth was one year old and had systemic JIA. However, others have presented a separate group of children with only anti-CCP and young age of onset [21]. 
Table 3 Analyses of autoantibodies in 147 patients from the Nordic JIA database followed for eight years in association with age at disease onset, number of cumulative joints, remission and articular damage

\begin{tabular}{|c|c|c|c|c|c|c|c|c|c|}
\hline & \multirow{2}{*}{$\begin{array}{l}\text { Total } \\
\text { n (\%) }\end{array}$} & \multicolumn{2}{|l|}{$\begin{array}{l}\text { Age at onset } \\
(n=147)\end{array}$} & \multicolumn{2}{|c|}{$\begin{array}{l}\text { Cumulative joints } \\
\text { during the first eight } \\
\text { years of disease }(n=147)\end{array}$} & \multicolumn{2}{|l|}{$\begin{array}{l}\text { Remission after } \\
8 \text { years }(n=147)\end{array}$} & \multicolumn{2}{|l|}{$\begin{array}{l}\text { Articular damage*** } \\
\text { at eight year follow } \\
\text { up }(n=147)\end{array}$} \\
\hline & & Median (IQR) & $\mathrm{p}^{*}$ & Median (IQR) & $\mathrm{p}^{*}$ & $\begin{array}{l}\text { Number of patients } \\
\text { without remission/total } \\
\text { number (\%) }\end{array}$ & $p^{* *}$ & $\begin{array}{l}\text { Number of patients } \\
\text { with damage/total } \\
\text { number (\%) }\end{array}$ & $\mathrm{p}^{* *}$ \\
\hline Total cohort & 147 & $5.4(2.8-9.9)$ & & $8(3-15)$ & & $99 / 147$ (67\%) & & 18/147 (12) & \\
\hline IgM RF positive & $6(4.1 \%)$ & $10.5(13.0-13.4)$ & 0.002 & $8(2-20)$ & 0.79 & $3 / 6(50 \%)$ & 0.39 & $3 / 6(50)$ & 0.0068 \\
\hline IgA RF positive & $6(4.1 \%)$ & $11.4(7.6-13.2)$ & 0.07 & $16(4-18)$ & 0.57 & $1 / 6(17 \%)$ & 0.66 & $4 / 6(67)$ & 0.0001 \\
\hline Anti-CCP positive & $5(3.4 \%)$ & $11.0(6.0-12.6)$ & 0.15 & $18(4-22)$ & 0.89 & $1 / 5(20 \%)$ & 1.00 & $3 / 5(60)$ & 0.0007 \\
\hline $\begin{array}{l}\text { Anti-collagen II } \\
\text { positive }\end{array}$ & $5(3.4 \%)$ & $4.8(4.2-11.4)$ & 0.54 & $13(6-26)$ & 0.29 & $2 / 5(40 \%)$ & 0.66 & $2 / 5(40)$ & 0.0274 \\
\hline $\begin{array}{l}\text { Any conventional\# } \\
\text { antibody }\end{array}$ & & & & & & & & $5 / 11$ & 0.0004 \\
\hline Any antibodya & & & & & & & & $6 / 15$ & 0.0004 \\
\hline
\end{tabular}

*Mann-Whitney U test, as compared with patients without the corresponding autoantibody.

**Fisher's Exact Test, as compared with patients without the corresponding autoantibody.

***Articular damage at eight-year follow-up according to JADI-A (score 0-72).

\#Positive for one or more antibodies: IgM RF, IgA RF and/or anti-CCP.

aPositive for one or more antibodies: IgM RF, IgA RF, anti-CCP and/or anti-collagen II.

Two of the five anti-CCP positive patients had levels more than ten times higher than the rest of the group. This is in concordance with adult RA, where anti-CCP positive individuals generally have levels clearly above the cut-off [31]. Others have found anti-CCP levels to be higher in IgM RF-positive patients with JIA compared with IgM RF-negative patients [21]. A very high level of anti-CCP at diagnosis should most likely be considered in prognostic evaluation and risk assessment for articular damage in children with JIA [22].

Studies on IgA RF and joint damage in JIA are limited. In our study, we found the strongest association between
IgA RF and joint damage after eight years of disease. This is supported by two previous studies presenting an increased risk for joint space narrowing or erosions in JIA patients with IgA RF [5,17]. In adults, a number of studies have indicated IgA RF as a stronger predictor for poor radiological prognosis than IgM RF [32,33]. High levels of IgA RF have also been shown to predict poor response to TNF inhibition in RA [34].

Only six patients were positive for anti-CII antibodies in our study, but the association with joint damage was statistically significant. Interestingly, this group of children had a median age of onset of 6.4 years, very close

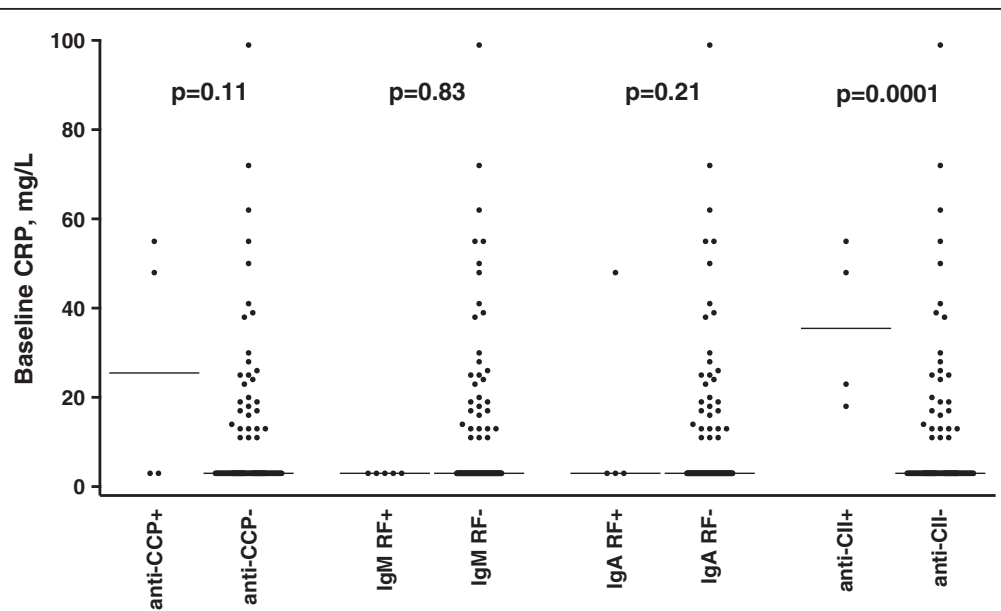

Figure 1 Association between the occurrence of four autoantibodies and early CRP levels in 134 (of 192) patients with JIA where blood samples were obtained $\leq 10$ months after onset of disease. P-values denote differences in median CRP levels between patients with and without the corresponding autoantibodies investigated with the Mann-Whitney's $U$ test. Horizontal lines indicate median levels. All CRP levels $\leq 10 \mathrm{mg} / \mathrm{L}$ were set to $3 \mathrm{~g} / \mathrm{L}$. 
to that of the total cohort, in contrast to the IgM RF and anti-CCP positive patients, who had a higher age of onset (Table 3). The young age at onset and the low frequency of overlap with the other autoantibodies indicate that the anti-CII JIA phenotype might differ from the $\mathrm{RF} /$ anti-CCP positive phenotypes. In RA, elevated levels of anti-CII at diagnosis represent an acute onset phenotype with high CRP [11,12], whereas anti-CCP and RFpositive individuals do not differ from autoantibodynegative individuals at baseline, but have a significantly poorer prognosis [35]. Anti-CII and anti-CCP do not only represent clinically opposite phenotypes in adult RA, but their occurrence is statistically inversely related [11]. Our result of an increased risk of joint damage after eight years of disease in anti-CII positive JIA patient differs from findings in adult RA, where anti-CII positive individuals have acute inflammation [11] and more radiological destructions [12] at disease onset, but not later, when levels of anti-CII decline. Although the number of anti-CII positive JIA patients is low, our study indicates that CRP levels are high during early disease in anti-CII positive children with JIA, as they are in adults with RA. In the present study, the median early CRP level was more than four times higher among anti-CII positive than among anti-CII negative JIA patients. In a previous study, using exactly the same anti-CII ELISA as employed in this study, the mean CRP levels were increased 2.5-fold at the time of diagnosis in anti-CII positive adult RA patients (53 vs $21 \mathrm{mg} / \mathrm{l}, \mathrm{p}<$ 0.0001) [11]. We hypothesize that these elevated CRP levels in anti-CII positive JIA patients may be due to production of proinflammatory cytokines by monocytes stimulated with anti-CII containing immune complexes, as was described in adult RA $[11,13]$.

We do not know how anti-CII develops over time in JIA patients. In adult RA, levels are not increased before diagnosis [15] and quickly decrease after [11,16]. If antiCII levels are only transiently elevated at the time of diagnosis in JIA, early serum sampling as employed in our study should be recommended.

We are only aware of one recent study on anti-CII in JIA [17]. In that study, encompassing 95 patients with disease duration varying between 0.4 and 9.5 (median 2.0) years and thus with later serum sampling than in our study, $17.9 \%$ had antibodies against native CII [11]. Anti-CII were not associated with more joint erosions at the time of serum sampling, but the study did not include any clinical or radiological follow-up data to evaluate the prognostic impact of anti-CII [17].

Our findings suggest that occurrence of anti-CII, antiCCP, IgM RF or IgA RF analysed at an early stage of disease may predict later joint damage. We suggest analysis of IgM and IgA RF as well as anti-CCP in all newly diagnosed children with JIA. We also suggest special attention to patients with more than one of these autoantibodies present. The role for anti-CII in JIA should be more extensively studied.

\section{Conclusions}

Occurrence of anti-CII, anti-CCP, IgM RF or IgA RF analysed at an early stage of disease may predict later joint damage. Patients with more than one of these autoantibodies present merit special attention. Anti-CII in JIA seems to characterize a different subset of JIA patients than the other antibodies, associated with increased CRP levels early after disease onset, and with clinical joint damage after eight years.

\section{Competing interests}

The authors declare that they have no competing interests.

\section{Authors' contributions}

All authors were involved in drafting the article or revising it critically for important intellectual content. All authors also approved the final version to be published and agreed to be accountable for all aspects of the work. Dr. LB had full access to all data in the study and takes responsibility for the integrity of the data and the accuracy of the data analysis. $L B, J R$ study conception and design. LB, EN, AF, KA, TH, SN, MR, MZ, JR acquisition of data. LB, JR analysis and interpretation of data.

\section{Acknowledgements}

On behalf of Nordic Study Group of Pediatric Rheumatology (NoSPeR) We thank the other members of the Nordic Study group of Pediatric Rheumatology (NoSPeR): Gudmund Marhaug in Trondheim, Freddy Karup Pedersen in Copenhagen, Suvi Peltoniemi in Helsinki and Boel AndersonGäre in Jönköping, Sweden. Lastly, we thank participating physicians who contributed by collecting data: Astri Lang and Anne Elisabeth Ross in Tromsø, Kjell Berntzen and Nina Moe in Trondheim, Mikael Damgaard, Maria Ekelund and Nils Olof Jonsson, Jönköping, Anders Berner and Hans Ekström, Karlstad, Eric Ronge, Skövde, Agne Lind and Lars Hammarén, Borås, Johan Robinsson, Trollhättan and Anna-Lena Nilsson, Östersund.

This work was supported by grants from the Department of Women's and Children's Health, Uppsala University Hospital, Uppsala, the Gillbergska foundation, Uppsala, the Swedish Research Council, the Swedish

Rheumatism Association, the Queen Silvia Children's Hospital, Göteborg, and the Dalarna Clinical Research Institute, Falun, Sweden.

\section{Author details}

'Department of Women's and Children's Health, Uppsala University, Uppsala, Sweden. ${ }^{2}$ Department of Pediatrics, University Hospital of North Norway, Tromsø, Norway. ${ }^{3}$ Institute of Clinical Medicine, University of Tromsø, Tromsø, Norway. ${ }^{4}$ Department of Pediatrics, University of Gothenburg, Gothenburg, Sweden. ${ }^{5}$ Department of Pediatrics, Children's Hospital, Helsinki University Hospital, Helsinki, Finland. ${ }^{6}$ Århus University Hospital, Skejby, Århus, Denmark. ${ }^{7}$ University Clinic of Pediatrics II, Rigshospitalet, Copenhagen, Denmark. ${ }^{8}$ Department of Laboratory Medicine, Children's and Women's Health, Norwegian University of Science and Technology, Trondheim, Norway. ${ }^{9}$ Department of Pediatrics, St. Olavs Hospital, Trondheim, Norway. ${ }^{10}$ Department of Immunology, Genetics and Pathology, Uppsala University, Uppsala, Sweden.

Received: 18 February 2014 Accepted: 6 June 2014

Published: 11 June 2014

\section{References}

1. Nordal E, Zak M, Aalto K, Berntson L, Fasth A, Herlin T, Lahdenne P, Nielsen $S$, Straume B, Rygg M: Ongoing disease activity and changing categories in a long-term nordic cohort study of juvenile idiopathic arthritis. Arthritis Rheum 2011, 63(9):2809-2818.

2. Petty RE, Southwood TR, Manners P, Baum J, Glass DN, Goldenberg J, He X, Maldonado-Cocco J, Orozco-Alcala J, Prieur AM, Suarez-Almazor ME, Patricia W, and International League of Associations for Rheumatology: International League of Associations for Rheumatology classification of 
juvenile idiopathic arthritis: second revision, Edmonton, 2001. J Rheumatol 2004, 31(2):390-392.

3. Modesto C, Anton J, Rodriguez B, Bou R, Arnal C, Ros J, Tena X, Rodrigo C, Rotes I, Hermosilla E, Barceló P: Incidence and prevalence of juvenile idiopathic arthritis in Catalonia (Spain). Scand J Rheumatol 2010, 39(6):472-479.

4. Berntson L, Andersson Gare B, Fasth A, Herlin T, Kristinsson J, Lahdenne P, Marhaug G, Nielsen S, Pelkonen P, Rygg M: Incidence of juvenile idiopathic arthritis in the Nordic countries. a population based study with special reference to the validity of the ILAR and EULAR criteria. $J$ Rheumatol 2003, 30(10):2275-2282

5. Gilliam BE, Chauhan AK, Low JM, Moore TL: Measurement of biomarkers in juvenile idiopathic arthritis patients and their significant association with disease severity: a comparative study. Clin Exp Rheumatol 2008, 26(3):492-497.

6. Rantapaa-Dahlqvist S, de Jong BA, Berglin E, Hallmans G, Wadell G, Stenlund $H$, Sundin $U$, van Venrooij WJ: Antibodies against cyclic citrullinated peptide and IgA rheumatoid factor predict the development of rheumatoid arthritis. Arthritis Rheum 2003, 48(10):2741-2749.

7. Aletaha D, Neogi T, Silman AJ, Funovits J, Felson DT, Bingham CO 3rd, Birnbaum NS, Burmester GR, Bykerk VP, Cohen MD, Combe B, Costenbader KH, Dougados M, Emery P, Ferraccioli G, Hazes JMW, Hobbs K, Huizinga TWJ, Kavanaugh A, Kay J, Kvien TK, Laing T, Mease P, Ménard HA, Moreland LW, Naden RL, Pincus T, Smolen JS, Stanislawska-Biernat E, Symmons D, et al: 2010 Rheumatoid arthritis classification criteria: an American College of Rheumatology/European League Against Rheumatism collaborative initiative. Arthritis Rheum 2010, 62(9):2569-2581.

8. van Rossum $M$, van Soesbergen $R$, de Kort $S$, ten Cate $R$, Zwinderman AH, de Jong B, Dijkmans B, van Venrooij WJ: Anti-cyclic citrullinated peptide (anti-CCP) antibodies in children with juvenile idiopathic arthritis. $J$ Rheumatol 2003, 30(4):825-828

9. Avcin T, Cimaz R, Falcini F, Zulian F, Martini G, Simonini G, Porenta-Besic V, Cecchini G, Borghi MO, Meroni PL: Prevalence and clinical significance of anti-cyclic citrullinated peptide antibodies in juvenile idiopathic arthritis. Ann Rheum Dis 2002, 61(7):608-611.

10. Hromadnikova I, Stechova K, Pavla V, Hridelova D, Houbova B, Voslarova S, Nekvasilova H, Vavrinec J: Anti-cyclic citrullinated peptide antibodies in patients with juvenile idiopathic arthritis. Autoimmunity 2002, 35(6):397-401.

11. Mullazehi M, Mathsson L, Lampa J, Rönnelid J: High anti-collagen type-II antibody levels and induction of proinflammatory cytokines by anticollagen antibody-containing immune complexes in vitro characterise a distinct rheumatoid arthritis phenotype associated with acute inflammation at the time of disease onset. Ann Rheum Dis 2007, 66(4):537-541.

12. Mullazehi M, Wick MC, Klareskog L, van Vollenhoven R, Rönnelid J: Anti-type II collagen antibodies are associated with early radiographic destruction in rheumatoid arthritis. Arthritis Res Ther 2012, 14(3):R100

13. Mullazehi M, Mathsson L, Lampa J, Rönnelid J: Surface-bound anti-type II collagen-containing immune complexes induce production of tumor necrosis factor alpha, interleukin-1beta, and interleukin-8 from peripheral blood monocytes via Fc gamma receptor IIA: a potential pathophysiologic mechanism for humoral anti-type II collagen immunity in arthritis. Arthritis Rheum 2006, 54(6):1759-1771.

14. Kim WU, Yoo WH, Park W, Kang YM, Kim SI, Park JH, Lee SS, Joo YS, Min JK, Hong YS, Lee SH, Park SH, Cho CS, Kim HY: IgG antibodies to type II collagen reflect inflammatory activity in patients with rheumatoid arthritis. J Rheumatol 2000, 27(3):575-581.

15. Mottonen T, Hannonen P, Oka M, Rautiainen J, Jokinen I, Arvilommi H, Palosuo T, Aho K: Antibodies against native type II collagen do not precede the clinical onset of rheumatoid arthritis. Arthritis Rheum 1988, 31(6):776-779.

16. Cook AD, Rowley MJ, Mackay IR, Gough A, Emery P: Antibodies to type II collagen in early rheumatoid arthritis. correlation with disease progression. Arthritis Rheum 1996, 39(10):1720-1727.

17. Gilliam BE, Chauhan AK, Moore TL: Evaluation of anti-citrullinated type II collagen and anti-citrullinated vimentin antibodies in patients with juvenile idiopathic arthritis. Pediatr Rheumatol Online J 2013, 11(1):31.

18. Wallace CA, Ruperto N, Giannini E: Preliminary criteria for clinical remission for select categories of juvenile idiopathic arthritis. J Rheumatol 2004, 31(11):2290-2294.

19. Viola S, Felici E, Magni-Manzoni S, Pistorio A, Buoncompagni A, Ruperto N, Rossi F, Bartoli M, Martini A, Ravelli A: Development and validation of a clinical index for assessment of long-term damage in juvenile idiopathic arthritis. Arthritis Rheum 2005, 52(7):2092-2102.
20. Arnett FC, Edworthy SM, Bloch DA, McShane DJ, Fries JF, Cooper NS, Healey LA, Kaplan SR, Liang MH, Luthra HS: The American Rheumatism Association 1987 revised criteria for the classification of rheumatoid arthritis. Arthritis Rheum 1988, 31(3):315-324

21. Tebo AE, Jaskowski T, Davis KW, Whiting A, Clifford B, Zeft A, McNally B, Hill HR, Bohnsack J, Prahalad S: Profiling anti-cyclic citrullinated peptide antibodies in patients with juvenile idiopathic arthritis. Pediatr Rheumatol Online J 2012, 10(1):29.

22. Kasapcopur O, Altun S, Aslan M, Karaarslan S, Kamburoglu-Goksel A, Saribas S, Arisoy N, Kocazeybek B: Diagnostic accuracy of anti-cyclic citrullinated peptide antibodies in juvenile idiopathic arthritis. Ann Rheum Dis 2004 63(12):1687-1689.

23. Kuna AT, Lamot L, Miler M, Harjacek M, Simundic AM, Vrkic N: Antibodies to mutated citrullinated vimentin and antibodies to cyclic citrullinated peptides in juvenile idiopathic arthritis. Clin Chem Lab Med 2009, 47(12):1525-1530.

24. Bukhari M, Lunt M, Harrison BJ, Scott DG, Symmons DP, Silman AJ: Rheumatoid factor is the major predictor of increasing severity of radiographic erosions in rheumatoid arthritis: results from the Norfolk Arthritis Register Study, a large inception cohort. Arthritis Rheum 2002, 46(4):906-912

25. Bas S, Genevay S, Meyer O, Gabay C: Anti-cyclic citrullinated peptide antibodies, IgM and IgA rheumatoid factors in the diagnosis and prognosis of rheumatoid arthritis. Rheumatology (Oxford) 2003, 42(5):677-680.

26. Omar A, Abo-Elyoun I, Hussein H, Nabih M, Atwa H, Gad S, Emad Y: Anticyclic citrullinated peptide (anti-CCP) antibody in juvenile idiopathic arthritis (JIA): correlations with disease activity and severity of joint damage (a multicenter trial). Joint Bone Spine 2013, 80(1):38-43.

27. Gilliam BE, Reed MR, Chauhan AK, Dehlendorf AB, Moore TL: Evidence of fibrinogen as a target of citrullination in IgM rheumatoid factor-positive polyarticular juvenile idiopathic arthritis. Pediatr Rheumatol Online J 2011, 9:8

28. Kwok JS, Hui KH, Lee TL, Wong W, Lau YL, Wong RW, Kim DL, Jones BM: Anti-cyclic citrullinated peptide: diagnostic and prognostic values in juvenile idiopathic arthritis and rheumatoid arthritis in a Chinese population. Scand J Rheumatol 2005, 34(5):359-366.

29. Dewint P, Hoffman IE, Rogge S, Joos R, Union A, Dehoorne J, Delanghe J, Veys EM, De Keyser F, Elewaut D: Effect of age on prevalence of anticitrullinated protein/peptide antibodies in polyarticular juvenile idiopathic arthritis. Rheumatology (Oxford) 2006, 45(2):204-208.

30. Syed RH, Gilliam BE, Moore TL: Rheumatoid factors and anticyclic citrullinated peptide antibodies in pediatric rheumatology. Curr Rheumatol Rep 2008, 10(2):156-163.

31. Rönnelid J, Wick MC, Lampa J, Lindblad S, Nordmark B, Klareskog L, van Vollenhoven RF: Longitudinal analysis of citrullinated protein/peptide antibodies (anti-CP) during 5 year follow up in early rheumatoid arthritis: anti-CP status predicts worse disease activity and greater radiological progression. Ann Rheum Dis 2005, 64(12):1744-1749.

32. Jonsson T, Arinbjarnarson S, Thorsteinsson J, Steinsson K, Geirsson AJ, Jonsson $\mathrm{H}$, Valdimarsson $\mathrm{H}$ : Raised IgA rheumatoid factor (RF) but not IgM RF or IgG RF is associated with extra-articular manifestations in rheumatoid arthritis. Scand J Rheumatol 1995, 24(6):372-375.

33. Jorgensen C, Legouffe MC, Bologna C, Brochier J, Sany J: IgA isotype rheumatoid factor in rheumatoid arthritis: clinical implications. Clin Exp Rheumatol 1996, 14(3):301-304

34. Bobbio-Pallavicini F, Caporali R, Alpini C, Avalle S, Epis OM, Klersy C, Montecucco C: High IgA rheumatoid factor levels are associated with poor clinical response to tumour necrosis factor alpha inhibitors in rheumatoid arthritis. Ann Rheum Dis 2007, 66(3):302-307.

35. Mathsson L, Mullazehi M, Wick MC, Sjoberg $O$, van Vollenhoven R, Klareskog L, Rönnelid J: Antibodies against citrullinated vimentin in rheumatoid arthritis: higher sensitivity and extended prognostic value concerning future radiographic progression as compared with antibodies against cyclic citrullinated peptides. Arthritis Rheum 2008, 58(1):36-45.

doi:10.1186/1546-0096-12-22

Cite this article as: Berntson et al.: Anti-type II collagen antibodies, anti-CCP, IgA RF and IgM RF are associated with joint damage, assessed eight years after onset of juvenile idiopathic arthritis (JIA). Pediatric Rheumatology 2014 12:22. 